\title{
Yanal Yük ve Burulmaya Maruz Kalan H-şekilli Betonarme Perdelerin Yapisal Analizi
}

\author{
${ }^{1}$ Sila AVĞIN ve *1 M.Metin KÖSE \\ ${ }^{1}$ Mühendislik-Mimarlık Fakültesi, İnşaat Mühendisliği Bölümü, Kahramanmaraş Sütçü İmam Üniversitesi, Türkiye
}

\begin{abstract}
Özet
Son zamanlarda, perde duvarlar ile çok sayıda yüksek katlı betonarme bina tasarlanmış ve inşa edilmiştir. Mimari planlama gereklilikleri nedeniyle, bu perde duvarlar genellikle açık kesit tipindedir ve tipik olarak $\mathrm{H}$ şekillidir. $\mathrm{Bu}$ çalışmada $\mathrm{H}$ şeklindeki perde duvarın, eşzamanlı olarak yanal yük ve burulma altında analizi yapılmıştır. Tüm kesitler, kesme göçmesinden önce eğilme akmasına ulaşacak şekilde tasarlanmıştır. Deneyi yapılan kesitin test sonuçlarını doğrulamak için SAP2000 programında analizleri yapılmıştır. Açık kesitli perde duvarın elasto-plastik davranışı için plastik mafsal ile modelleme yapılmıştır. Perde duvarın modellemesinde eğilme ve kesme kapasitelerini analiz etmek için eğilme ve kesme mafsalları kullanılmıştır. SAP2000'de kesitin moment-eğrilik grafiği alınarak kesitin doğrusal olmayan davranışın incelenmiştir. Analiz sonucunda ulaşılan kesme kuvveti kapasitesinin, deneysel verilerden elde edilen kesme kuvveti kapasitesini çok yakın sonuçlar vermiştir.
\end{abstract}

Anahtar Kelimeler: Perde Duvar, Burulma, Plastik Mafsal, SAP2000

\section{Structural Capacities Of H-Shaped RC Core Wall Subjected to Lateral Load and Torsion}

\begin{abstract}
Recently, numerous high-rise reinforced concrete buildings with core walls have been designed and constructed. Due to architectural planning requirements, these core walls are generally of open crosssection and are typically $\mathrm{H}$-shaped. In this study, $\mathrm{H}$-shaped core wall was analyzed simultaneously under lateral load and torsion. All sections are designed to achieve flexural yielding before shear failure. In order to confirm the test results, the section was analyzed in SAP2000 program. Model is made with plastic joint for elasto-plastic behavior of open section wall. flexural and shear hinges were used to analyze the flexural and shear capacities of the core wall modeling. In SAP2000, the moment-curvature graph of the cross section is taken and the nonlinear behavior of the cross section is examined. The shear force capacity obtained from the analysis yielded very close results to the shear force capacity obtained from the experimental data.
\end{abstract}

Key words: Core wall, Torsion, Plastic Hinge, SAP2000

\section{Giriş}

Depremsellik yönünden aktif bölgelerdeki yapılarda betonarme perdelerin kullanımı yaygındır. Son zamanlarda, perde duvar ile birçok yüksek katlı betonarme yapı tasarlanmış ve inşa edilmiştir. $\mathrm{Bu}$ perde duvarlar genellikle açık kesit tipindedir, tipik olarak $\mathrm{H}$ şeklindedir. Perde duvarlar bir depremde eşzamanlı olarak yanal yük ve burulmaya maruz kalabilirler. Betonarme perdelerin depremde gösterdiği davranışları incelendiğinde burulma etkisinin en aza indirilmesi önemlidir. Burulma etkisi altındaki perdede hasarın boyutu; perdelerin plandaki yerleşimi, kesiti ve birçok etkene bağlı olarak değişir. Bundan dolayı betonarme perdelerin farklı yön ve değerlerde yatay yük

*Corresponding author: Sıla Avğın Address: Mühendislik-Mimarlık Fakültesi İnşaat Mühendisliği Bölümü, Kahramanmaraş Sütçü İmam Üniversitesi 40650 Kahramanmaraş TURKEY. E-mail address: silaavgin@ksu.edu.tr, Phone: +90344 3001661 
etkileri altında doğrusal olmayan analizlerle davranışlarının belirlenmesi günümüz yapı teknolojisinin gelişmesinde oldukça önemli bir paya sahiptir. Bir açık kesitli perde duvarının burulma rijitliği, bir kapalı kesitten daha küçüktür. Açık kesitli perde duvarın elasto-plastik kapasitelerinin kapalı kesitten daha düşük olduğu tahmin edilmektedir. Ancak açık kesitli betonarme perdenin elasto-plastik burulma momentinde az sayıda çalışma yapılmıştır. Eş zamanlı olarak yanal yük ve burulmaya maruz kalan açık kesitli bir perde duvarın yapısal kapasiteleri ile ilgili bilinmeyen faktörler vardır. Maksimum yanal kuvvet ile maksimum burulma mukavemeti arasındaki ilişki özellikle önemlidir. [1] Yanal yük ve burulmaya maruz kalan kolon veya kapalı kesit için tasarım prosedürü ACI yönetmeliğinde [2] tanımlanmıştır. ACI yönetmeliği burulma momentinin sınırını tanımlamaktadır. Bununla birlikte, eş zamanlı yanal yük ve burulmaya maruz kalan açık kesitli bir perde duvarın yapısal kapasiteleri ile ilgili bilinmeyen faktörler vardır. Sadece burulmaya maruz kalan kutu kesite benzer kapalı bir kesitin her bir levhası, sadece kesme durumuna maruz kalabilir. Açık kesitli perde duvar kesitinin çarpılmasından dolayı, flanş kısımları eğilme momentine ve kesmeye maruz kalırsa, ACI tasarım yöntemi açık kesitli perde duvarlarda burulma için uygulanamaz. Bu nedenle açık kesitli perde duvarların, özellikle H-kesitli perde duvarların, elasto-plastik davranışını belirlemek için deneysel ve analitik çalışmalar yapılmıştır. [1] Maruta ve ark. [1] aynı anda yanal yük ve burulmaya maruz kalan H-kesitli betonarme perdeleri deneysel ve analitik olarak çalışmışlardır. Yapılan çalışmada parametre olarak yanal yük yönü ve eğilme momentinin burulma momentine oranı alınarak 9 adet H-kesitli perde duvar deneysel olaral çalışılmıştır. Tüm kesitler eğilme göçmesine maruz kalacak şekilde tasarlanmıştır. Sonuçlara bakıldığında tüm kolonlar kesme göçmesinden önce eğilmeden dolayı göçmüştür. \%25 oranında burulma momenti oranına sahip olan numuneler kıyaslandığında güçlü eksen yanal yüklemesine (HS25) maruz kalan numunenin zayıf eksen ve çapraz eksen yüklemesine maruz kalan numunelerden daha iyi süneklik gösterdiği görülmüştür. Wallace ve Moehle [3] yapılan çalışmada depremde betonarme perdelerin performansı için mevcut kapasiteyi belirleyerek perde uç bölgelerinde oluşan donatı detaylandırılmasını incelemiş ve buna bağlı olarak bir analitik yöntem kullanmıştır. Çolakoğlu [4] yaptığı çalışmada U şekilli betonarme perdelerin farklı yatay yük altında etkilerini sonlu elemanlar yöntemi ile incelemiştir. $U$ şekilli betonarme perdelerde uygulanan yatay yük kayma merkezinden uzaklaştıkça kesitte oluşan burulma momentinin arttığı, burulma momenti etkisi ile de eğilme momenti kapasitesini azaldığı görülmüştür. Yatay yük perdenin kayma merkezine uygulandığında ise burulma momentinin oluşmadığı gözlemlenmiştir.

Bu çalışmada, Maruta ve ark. [1] tarafından yapılan deneysel çalışmada kullanılan perde duvarın SAP2000 programında perde kesitinin 1 boyutlu çubuk eleman olarak modellenerek deneysel sonuçlar ile karşılaştırılması amaçlanmaktadır.

\section{Deneysel Veriler}

Modellemede kullanılacak deneysel veriler, Maruta ve ark.[1] tarafindan yapılan deneysel çalışmalardan elde edilmiştir. Test numunesinin kesiti, detayları ve yükleme yönleri Şekil 1'de gösterilmiştir. Kolon $880 \mathrm{~mm} * 800 \mathrm{~mm}$ boyutlarında H kesiti şeklinde ve kolon yüksekliği 1200 mm dir. $16 \phi 10$ ve $46 \phi 6$ boyuna donatı kullanılmıştır.

Boyuna donatıların akma dayanımı sırasıyla $403 \mathrm{MPa}, 365 \mathrm{MPa}$ ve nihai dayanımları $595 \mathrm{MPa}$, $419 \mathrm{MPa}$ dır. Enine donatının akma dayanımı $365 \mathrm{MPa}$ ve nihai dayanımı $419 \mathrm{MPa}$ dır. Enine 
donatılar $150 \mathrm{~mm}$ eşit aralıkla yerleştirilmiştir. Pas payı $10 \mathrm{~mm}$ alınmıştır. Betonun belirlenen basınç dayanımı $60 \mathrm{MPa}$ 'dır.
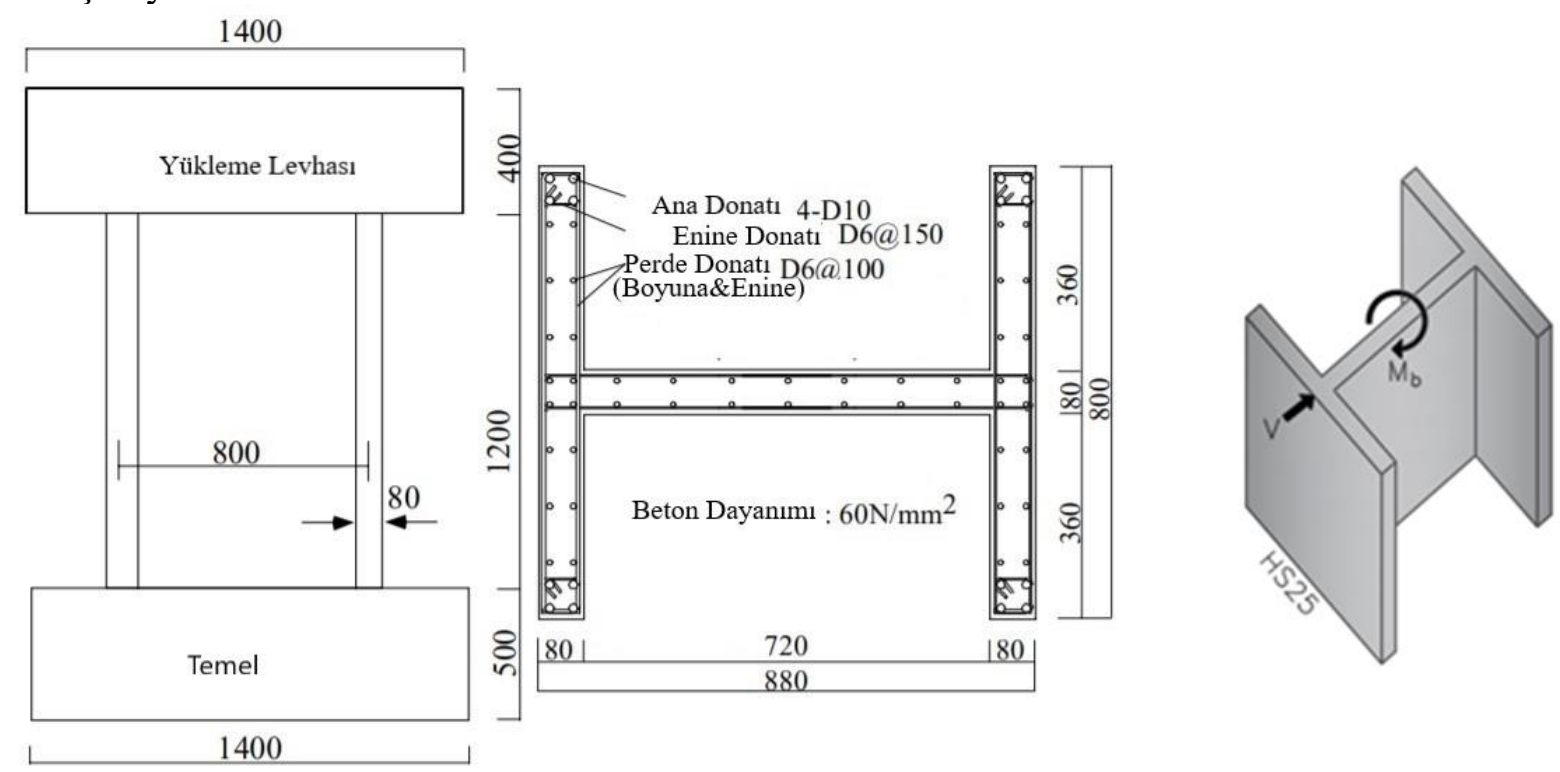

Şekil 1: Numune Detayları ve Yükleme Yönleri

\section{1. Çelik Modeli}

Donatı çeliği elastik davranış, akma bölgesi ve pekleşme bölgesi olarak 3 bölgede tanımlanmıştır. Bu çalışmada kullanılan donatı çeliği modeli TBDY 2018 [5] deki model alınarak oluşturulmuştur. Fakat TBDY'de akma bölgesi sabit olarak verilmektedir. Bu çalışmada SAP2000'de modelin iterasyona girebilmesi için akma bölgesinde elasitk bölgedeki elastisite modülünün \%10 u kadar bir katsayılık bir eğim verilmesi gerekmektedir. Bu çalışmada çelik modeli Denklem 1-3 den hesaplanmıştır:

$$
\begin{array}{ll}
f_{s}=E_{s} * \varepsilon_{s} & \varepsilon_{s} \leq \varepsilon_{s y} \\
f_{s}=f_{s y}+\left(\varepsilon_{s}-\varepsilon_{s h}\right) a E_{s} & \varepsilon_{s y} \leq \varepsilon_{s} \leq \varepsilon_{s h} \\
f_{s}=f_{s u}-\left(f_{s u}-f_{s h}\right)\left(\frac{\varepsilon_{s}-\varepsilon_{s h}}{\varepsilon_{u}-\varepsilon_{s h}}\right)^{2} & \varepsilon_{s h} \leq \varepsilon_{s} \leq \varepsilon_{u}
\end{array}
$$

burada, $f_{s}$ :çelik gerilmesi, $E_{s}$ :çeliğin elastisite modülü, $\varepsilon_{s}:$ çelik birim şekil değiştirmesi, $f_{s y}:$ Çelik akma dayanımı, $\varepsilon_{s y}$ :çelik akma birim şekil değiştirmesi, $\varepsilon_{s h}$ :çeliğin pekleşmeye başladığ şekil değiştirmesi, $f_{s u}$ :Çelik nihai dayanımı, $\varepsilon_{u}$ :Çelik nihai birim şekil değiştirmesi ve $a$ :akma platosunun eğimini tanımlayan bir katsayıdır. $(a=0.01)[5]$

\subsection{Beton Modeli}

Beton malzemesinin basınç davranışını modellemek için Geliştirilmiş Kent-Park Modeli [6] kullanılmıştır. Betonun gerilme-şekil değiştirme ilişkisi, enine donatı ile sarılması durumunda, sarılmamış duruma göre önemli farkl1lıklar gösterdiğinden dolayı, beton sargılı ve sargısız olmak üzere 2 farklı kategoride incelenmiştir. (Şek. 2) 
Çekme altında beton davranışı, Vecchio ve Collins [7] tarafindan geliştirilmiştir. Şekil 2.3b'de görüldüğü gibi, beton çekme gerilme-birim şekildeğiştirme ilişkisi, temel beton çekme gerilmesi $f_{c 1}$, temel beton çekme birim şekildeğiştirme $\varepsilon_{c 1}$ ile ilişkilendirmiştir. [7]

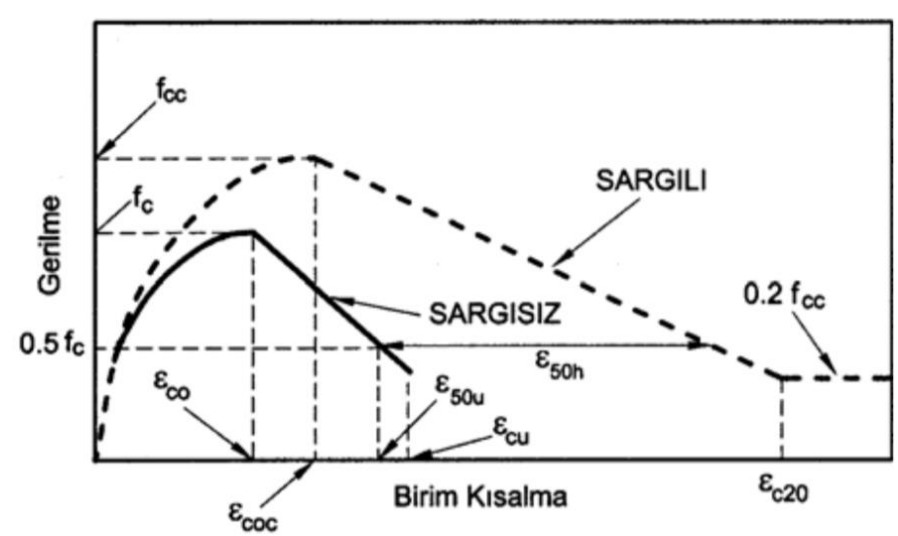

Şekil 2(a): Geliştirilmiş Kent ve Park modeline ait gerilme-şekildeğiştirme eğrisi

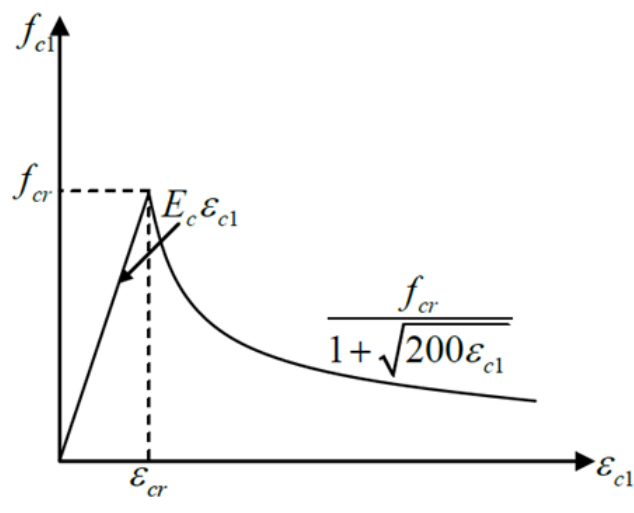

Şekil 2(b): Çekme davranışı altında beton modeli

Basınç davranış modelleri için, eğrilerin ilk bölümlerinin ikinci dereceden bir parabol olduğu varsayılmıştır. Gerilme azalmalarını yaşandığ ikinci bölümde ise eğimi eksi olan düz çizgilerle gösterilmiştir. Sargısız betonda maksimum birim şekildeğiştirme $\varepsilon_{\mathrm{cu}}$ 'dur. Sargısız betona ve sargılı betona ait denklemler sırası ile Denk.4-5 ve Denk.6-7'de verilmiştir.

$$
\begin{aligned}
& \sigma_{c}=f_{c}\left[\frac{2 \varepsilon_{c}}{\varepsilon_{c 0}}-\left(\frac{\varepsilon_{c}}{\varepsilon_{c 0}}\right)^{2}\right] \quad 0 \leq \varepsilon_{c} \leq \varepsilon_{c 0} \text { için } \\
& \begin{aligned}
\sigma_{c}=f_{c}\left[1-Z_{u}\left(\varepsilon_{c}-\varepsilon_{c 0}\right)\right] \quad \text { burada } & Z_{u} \\
& =\frac{0.5}{\varepsilon_{50 u}-\varepsilon_{c 0}} \quad \text { ve } \quad \varepsilon_{50 u}=\frac{3+0.285 * f_{c}}{142 * f_{c}-1000} \geq \varepsilon_{c o}
\end{aligned} \\
& \sigma_{c}=f_{c}\left[\frac{2 \varepsilon_{c}}{\varepsilon_{c 0 c}}-\left(\frac{\varepsilon_{c}}{\varepsilon_{c 0 c}}\right)^{2}\right] \quad 0 \leq \varepsilon_{c} \leq \varepsilon_{c 0} \quad \varepsilon_{c 0 c}=K * \varepsilon_{c 0} \quad K=1+\frac{\rho_{s} f_{y w k}}{f_{c}} \\
& \sigma_{c}=f_{c c}\left[1-Z_{c}\left(\varepsilon_{c}-\varepsilon_{c 0 c}\right)\right] \\
& \geq 0.2 * f_{c c} \text { burada } \\
& Z_{c} \quad \varepsilon_{50 h} \\
& =\frac{0.5}{\varepsilon_{50 u}+\varepsilon_{50 h}-\varepsilon_{c 0 c}} \text { ve } \quad=0.75 * \rho_{s}\left(\frac{b_{k}}{s}\right)^{1 / 2}
\end{aligned}
$$

burada, $\sigma_{c}$ : beton basınç gerilmesi, $f_{c}$ : sargısız betonun basınç dayanımı, $\varepsilon_{c 0}$ :sargısız betonda maksimum gerilme altındaki birim şekil değiştirme, $\varepsilon_{c}$ : beton birim şekil değiştirmesi, $Z_{u}$ : sargısız beton gerilme-birim şekil değiştirme eğrisinin doğrusal bölümünün eğimi, $f_{c c}$ : sargllı beton dayanımı $\left(f_{c c}=K * f_{c}\right), \varepsilon_{c 0 c}$ : sargılı betonda maksimum gerilme altındaki birim şekil değiştirme, $Z_{c}$ : sargılı beton gerilme-birim şekil değiştirme eğrisinin doğrusal bölümünün eğimi, $\rho_{s}$ : sargı donatısının hacimsel oranı, $\left(A_{0} l_{s} / s b_{k} h_{k}\right) b_{k}$ : striye dışından etriye dışına ölçülen çekirdek beton alanının küçük boyutu $(\mathrm{mm}), h_{k}$ : etriye dışından etriye dışına ölçülen çekirdek beton alanını büyük boyutu $(\mathrm{mm}), A_{0}: \operatorname{sarg} 1$ donatısı kesit alanı, $l_{s}$ : kesitteki sargı donatısı ve çirozların toplam uzunluğu $(\mathrm{mm}) s$ : sarg1 donatısı aralı̆̆ $1(\mathrm{~mm}), \varepsilon_{c 20}$ : sarg1l beton için $0.2 f_{c c}$ gerilme değerine karşılık gelen birim şekil değiştirme, $\varepsilon_{c u}$ : sargısız beton için en büyük birim şekil değiştirmedir.[6] 
Betonun çekme davranışın için,

$$
\begin{aligned}
& f_{c 1}=E_{c} * \varepsilon_{c 1} \quad 0 \leq \varepsilon_{c 1} \leq \varepsilon_{c r} \quad \varepsilon_{c r}=\frac{f_{c r}}{E_{c}} \quad E_{c}=\frac{2 * f_{c c}}{\varepsilon_{c c}} \\
& f_{c 1}=\frac{f_{c r}}{1+\sqrt{200 * \varepsilon_{c 1}}} \quad 0 \leq \varepsilon_{c 1} \leq \varepsilon_{c r} \quad f_{c r}=7.5 * \sqrt{f_{c c}}
\end{aligned}
$$

burada; $E_{c}$ : betonun elastisite modülü, $\varepsilon_{c r}$; betonun tek eksenli çatlama dayanımına karşılık gelen çatlama birim şekildeğiştirmesidir. [7]

\section{Deformasyon Modelleri}

Yanal yüklere ve burulmaya maruz kalan betonarme perdenin yanal deformasyonu; kesme ve eğilmeden kaynaklanan deformasyonların toplamıdır. Bu deformasyon modelleri, kesme ve eğilme mukavemetinin karşılaştırılmasına dayanan beş kategoriden birine sınıflandırılır. [8]

\section{1. Ĕ̈ilme Deformasyonu}

Bir betonarme kesitin eğilme tepkisi, moment-eğrilik analizi ile hesaplanır. Moment-eğrilik analizi, her malzemenin doğrusal olmayan davranışını doğru bir şekilde yansıtan beton ve donatı çeliği için yapısal modelleri kullanmaktadır. Kolon ucuna uygulanmış bir yanal yük için, moment kolonun herhangi bir noktasında belirlenebilir. Eğilme deformasyonlarından kaynaklanan bir kolonun yanal yerdeğiştirmesi, kolon yüksekliği boyunca eğrilik dağılımının integrasyonu ile hesaplanabilir.[9]

\subsection{Kesme Deformasyonu}

$\mathrm{Bu}$ araştırmada kullanılan kesme modeli Sezen [10] tarafından geliştirilen modeldir. Sezen'in kesme modeli Şekil 3'te gösterilmiştir. Model 4 nokta ile tanımlanmıştır.

\section{Kesme Kirllma Noktasl (A Noktasi)}

A Noktası olarak tanımlanan kesme çatlama noktası, genellikle eğilmeye bağlı olan betondaki ilk çatlamaya karşılık gelmez. Aksine, A Noktası, çapraz kesme çatlaklarının başladığını gösterir.

$$
\Delta_{c r}=\left(\frac{V_{c r} L}{G A_{g}}\right) \quad V_{c r}=\left(\frac{P}{2 f_{c} A_{g}}+0.1\right) \frac{\mathrm{GA}}{L} \quad \mathrm{G}=\frac{E_{c}}{2(1+\mu)}
$$

burada; $\mu$ : poisson oran1, $E_{c}$ : betonun elastisite modülüdür. $\mu$ normal ağırlıkta beton için $0.15-0.30$ arasındadır. $G$ betonun tanımlanmış kesme modülü, $P$ eksenel yük, $A_{g}$ alan, $L$ kolon yüksekliğidir. 


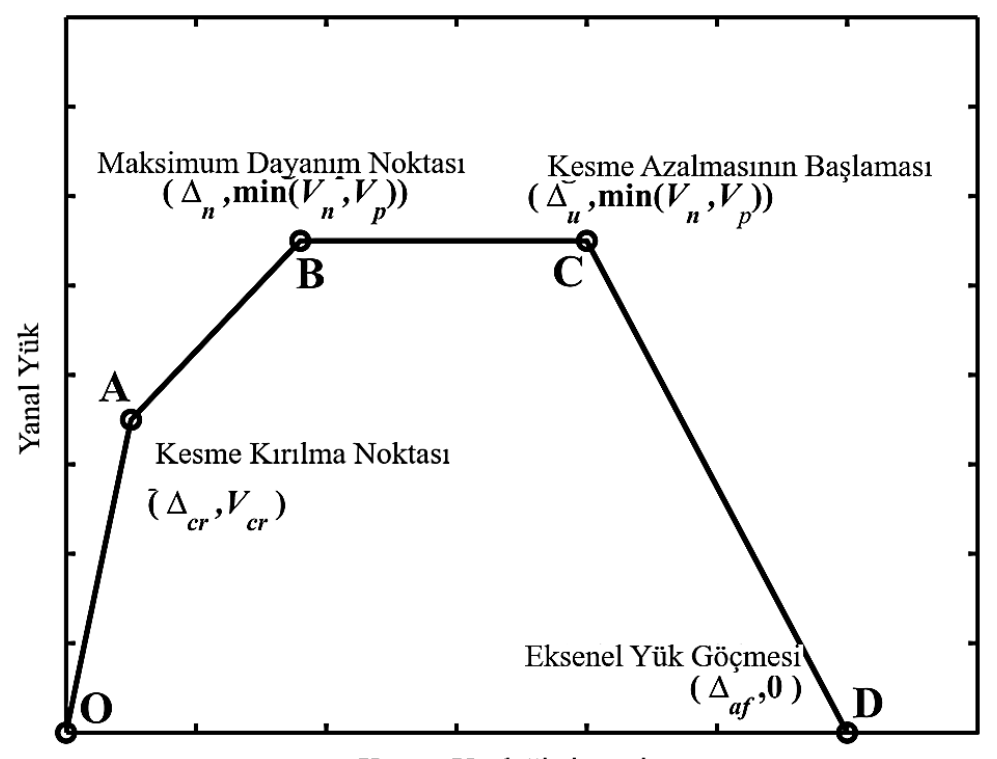

Kesme Yerdeğiştirmesi

Şekil 3: Yanal Yük- Kesme Yerdeğiştirme Ilişkisi[9]

\section{Maksimum Kesme Dayanım Noktası (B Noktası)}

Maksimum kesme dayanımını, bir betonarme kolonunun $V_{n}$ değerini tahmin etmek için mevcut olan birkaç model mevcuttur. Bu çalışmada Sezen (2006) tarafından önerilen model uyarlanmıştır.

$$
\begin{array}{cc}
V_{n}=k\left(V_{c}+V_{s}\right)=\left(\frac{0.5 \sqrt{f_{c}}}{a / d} \sqrt{1+\frac{P}{0.5 \sqrt{f_{c}} A_{g}}}\right) & 0.8 A_{g}+\left(\frac{A_{s p} f_{y w} d_{c}}{s}\right) \\
\gamma_{n}=\frac{1}{5000} \frac{f_{y l} \rho_{l}}{(a / d) \sqrt{\frac{P}{A_{g} f_{c}}}}-0.0004 & \Delta_{v, n}=\gamma_{n} L
\end{array}
$$

burada, $V_{c}$ : beton katkısı, $V_{s}$ : etriye donatı katkısı, $a$ kesme açıklı̆ ve $d$ etkili derinlik, $A_{s p}$ : yük yönünde enine donatının alanı, $f_{y w}$ : enine donatının akma gerilmesi, $f_{y l}$ : boyuna çelik akma dayanımı (ksi), $\rho_{l}$ : boyuna çelik donatı oranıdır.l $\rho_{l}$ yüzde cinsinden ifade edilir.

\section{Kesme Azalmasının Başlangıc Noktası (Nokta C)}

Gerin ve Adebar [11], kesme dayanım azalmasının başladığı bir noktayı tanımlar. Ancak, onların modelleri, akma ve kesme şekildeğiştirmesi sünekliğinde teorik bir kesme yerdeğiştirmesine dayanmaktadır.

$$
\gamma_{u}=\left(4-12 \frac{v_{n}}{f_{c}^{\prime}}\right) \gamma_{n} \quad \Delta_{v, u}=\gamma_{u} L
$$

burada; $v_{n}$ : tepe mukavemetindeki kesme gerilmesidir. $\left(V_{\text {peak }} / b d\right)$ 


\section{Eksenel Yük Taşıma Kaybı Kapasitesi (Nokta D).}

Kesme dayanım azalması başlangıcından sonra, kesme dayanımı, eksenel yük göçmesi noktasına artan kesme deformasyonuyla lineer olarak azalır. Eksenel yük göçmesinde yanal kuvvetin sıfır olduğu varsayılır.

$$
\Delta_{A L F}=\frac{4}{100}\left[\frac{1+\tan ^{2} \theta}{\tan \theta+P\left(\frac{s}{A_{s p} f_{y w} d_{c} \tan \theta}\right)}\right]
$$

burada $\theta$ kesme kırılma açısı ve bu açının 65 derece olduğu kabul edilir.[10]

\subsection{Toplam Deformasyon}

Yanal yüklemeye maruz kalan bir kolonun tepkisini modellemek için, deformasyon bileşenleri dikkate alınmalıdır. Deformasyon bileşenlerinin her biri, kolonun tepe direncine kadar toplam tepkiyi elde etmek için basitçe eklenebilir. Bununla birlikte, tepe sonrası davranışlarda kolon kesme, akma ve eğilme dayanımlarının karşılaştırılmasına dayanan beş kategoriden birine sınıflandırılır ve her bir kategori için deformasyon bileşenlerinin kombinasyonu için belirlenir. (Şek. 4)

$$
\text { Kategori-1 }\left(\boldsymbol{V}_{\boldsymbol{n}}<\boldsymbol{V}_{\boldsymbol{y}}\right)
$$

Kolon eğilme davranışında elastik kalırken, kesmeden kaynaklı olarak göçer.

$$
\text { Kategori-2 }\left(\boldsymbol{V}_{\boldsymbol{y}} \leq \boldsymbol{V}_{\boldsymbol{n}} \leq \mathbf{0 . 9 5} \boldsymbol{V}_{\boldsymbol{p}}\right)
$$

Kesme kuvveti, eğilme mukavemetinden daha azdır ve kolon kesmede başarısızdır.

$$
\text { Kategori-3 }\left(\mathbf{0 . 9 5} \boldsymbol{V}_{\boldsymbol{p}} \leq \boldsymbol{V}_{\boldsymbol{n}} \leq \mathbf{1 . 0 5} \boldsymbol{V}_{\boldsymbol{p}}\right)
$$

Kesme ve eğilme dayanımı neredeyse aynıdır. Kesme ve eğilme göçmesinin "eşzamanlı olarak" gerçekleştiği varsayılır.

$$
\text { Kategori-4 }\left(\mathbf{1 . 0 5} \boldsymbol{V}_{\boldsymbol{p}}<\boldsymbol{V}_{\boldsymbol{n}} \leq \mathbf{1 . 4} \boldsymbol{V}_{\boldsymbol{p}}\right)
$$

Kesme mukavemeti eğilme mukavemetinden daha büyüktür ve kolon eğilme sırasında göçebilir,

$$
>\text { Kategori-5 }\left(\boldsymbol{V}_{\boldsymbol{n}}>\mathbf{1 . 4} \boldsymbol{V}_{\boldsymbol{p}}\right)
$$

Kolon kesme davranışında elastik kalırken, eğilmeden kaynaklı olarak göçer.[12] 


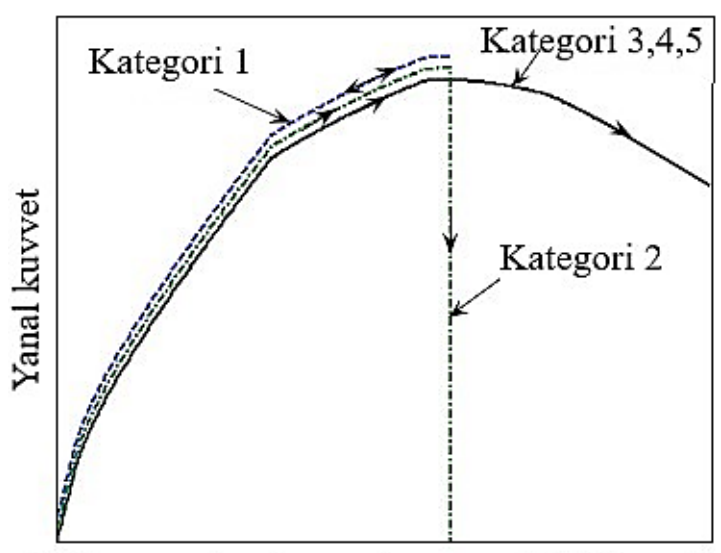

Eğilme ve donatı sıyrılması yerdeğiştirmesi

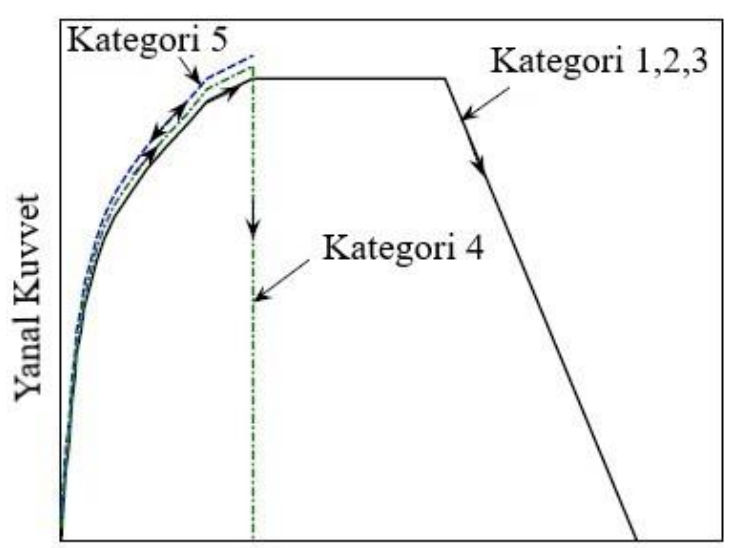

Kesme yerdeğiștirmesi

Şekil 4: Her kategori için eğilme, donatı sıyrılması ve kesme davranış modeli [12]

\section{Analitik Modelleme}

\subsection{Malzeme Modelleri}

Bölüm 2.1'de anlatılan formüllere dayanarak çeliğin gerilme-birim şekil değiştirme grafiği Şekil 5' te gösterilmiştir. Şekil 6'da Geliştirilmiş Kent-Park beton modelinin sargısız beton ve sargılı beton için kullanımı karşılaştırmalı olarak verilmiştir. Sargısız beton modelinde, betonun maksimum gerilmeye ulaştığı birim şekil değiştirme değeri $\left(\varepsilon_{c 0}\right) 0.002$ olarak alınır.

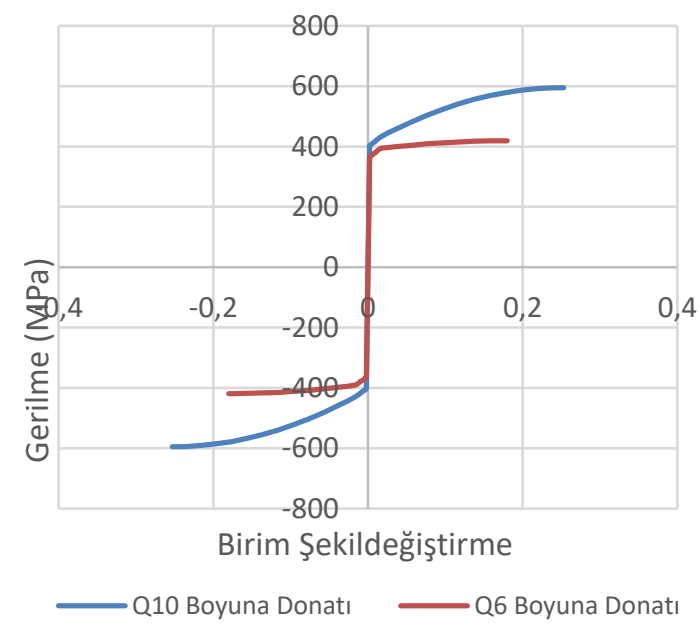

Şekil 5(a): Çelik modeli

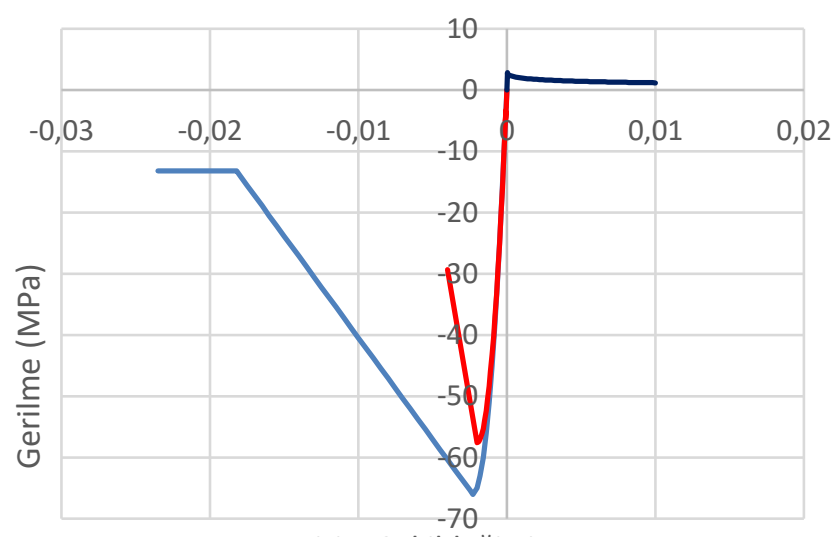

Birim Şekildeğiştirme

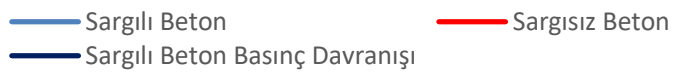

Şekil5(b): Sargıl1-sargısız beton modeli

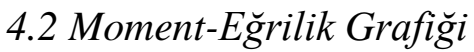

$\mathrm{Bu}$ çalışmada betonarme kolonların moment- eğrilik grafiğini elde edebilmek için kesit analiz programı (SAP2000) kullanılmıştır. Elde edilen grafik Şekil 6’da gösterilmektedir. 

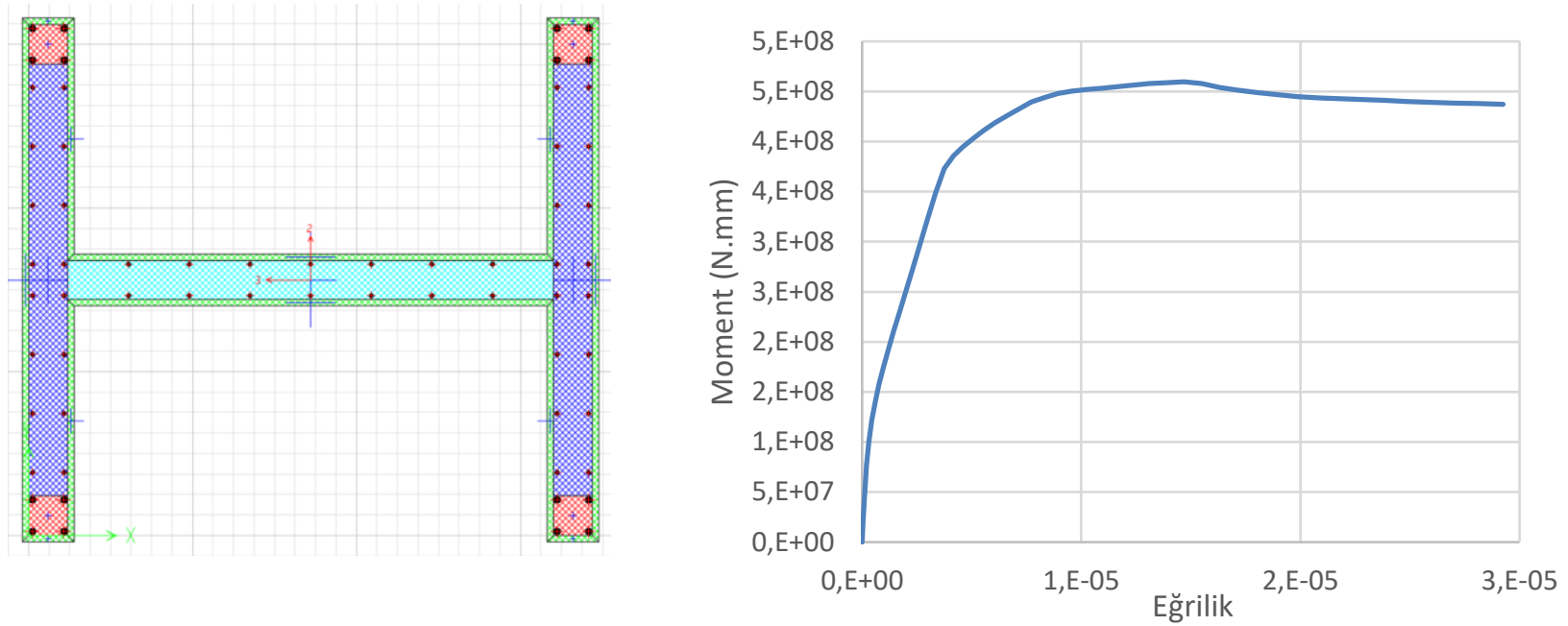

Şekil 6: SAP2000 perde kesiti ve Moment-Eğrilik Grafiği

\subsection{Toplam Deformasyon Modellenmesi}

Çalışmada SAP2000 programında analiz yapılmıştır. Toplam deformasyon için; eğilmede 0,5 aralıkla her noktaya bir mafsal, kesmede ise en alt noktasına 1 mafsal yerleştirilmiştir. $\mathrm{Bu}$ mafsallara model olarak bahsedilen modeller moment-eğrilik ya da moment-dönme eğrisi olarak Şekil 7'de gösterildiği gibi girilmiştir.

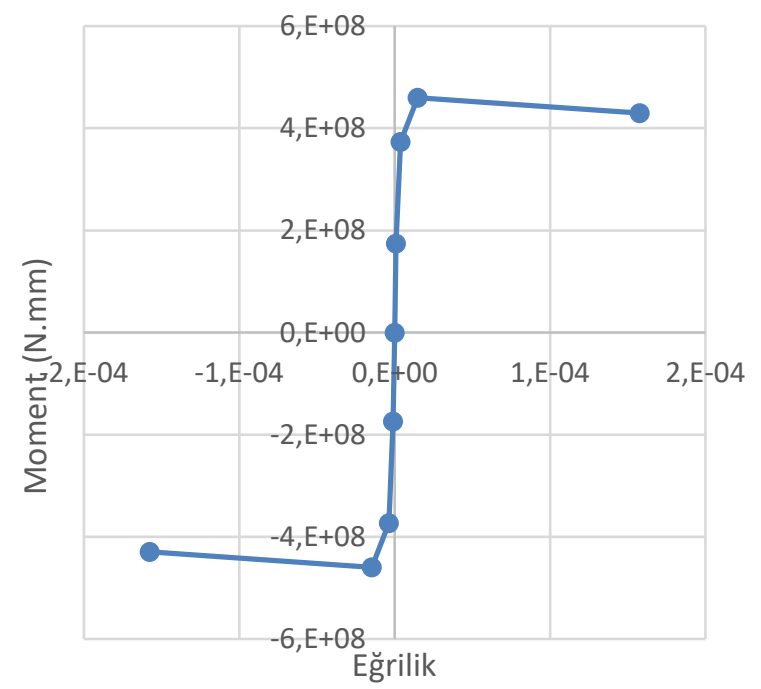

Şekil7 (a): Eğilme deformasyonu için moment-eğrilik

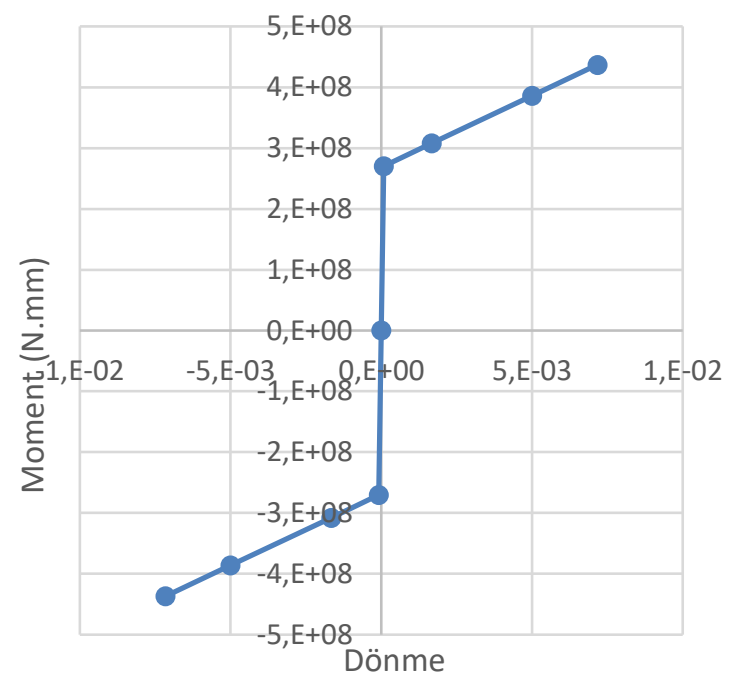

Şekil7 (b): Kesme deformasyonu için moment-dönme

\subsection{SAP2000 modeli}

Modellemede kullanılacak olan perde modeli için, TBDY 2018'de bazı sınırlandırmalar getirilmiştir. Şekil 8'de gösterildiği gibi enkesit şekli dikdörtgen, I, T, L, U veya C olan perdeler, plandaki en büyük perde kolu uzunluğunun toplam perde yüksekliğine oranının 1/2'yi aşmadığ durumlarda, ekseni enkesit ağırlık merkezinden geçen eşdeğer çubuk sonlu eleman olarak 
modellenebilirler.

$$
\frac{L_{\text {en uzun kol }}}{H_{\text {toplam perde yüksekliği }}} \leq \frac{1}{2}
$$

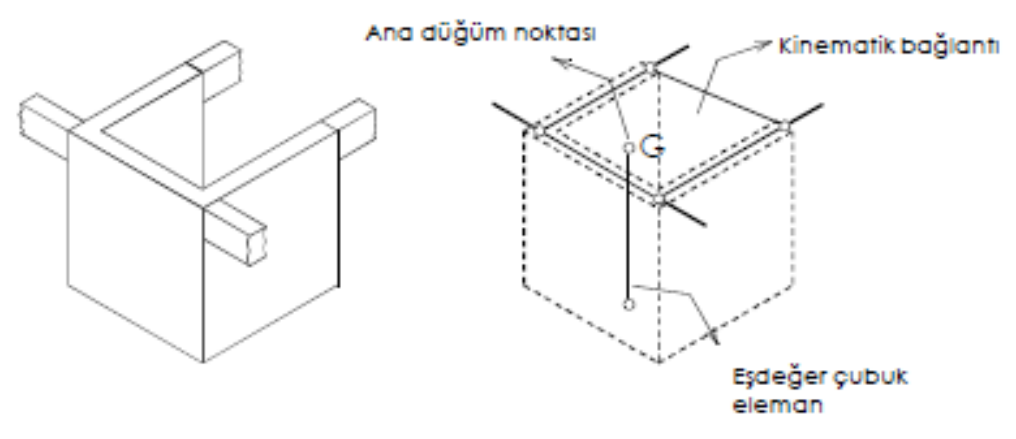

Şekil 8: Perde duvarların eşdeğer çubuk olarak modellenmesi

Şekil 9'da gösterilen perde modeli çubuk eleman olarak çizilmiştir. Bu çalışmada en uzun kol uzunluğu $880 \mathrm{~mm}$, toplam perde yüksekliği $1200 \mathrm{~mm}$ olup oranı 0.73 'tür. Perde duvara eğilme ve kesme için yerleştirilen mafsallar da Şekil 9'da gösterilmiştir.
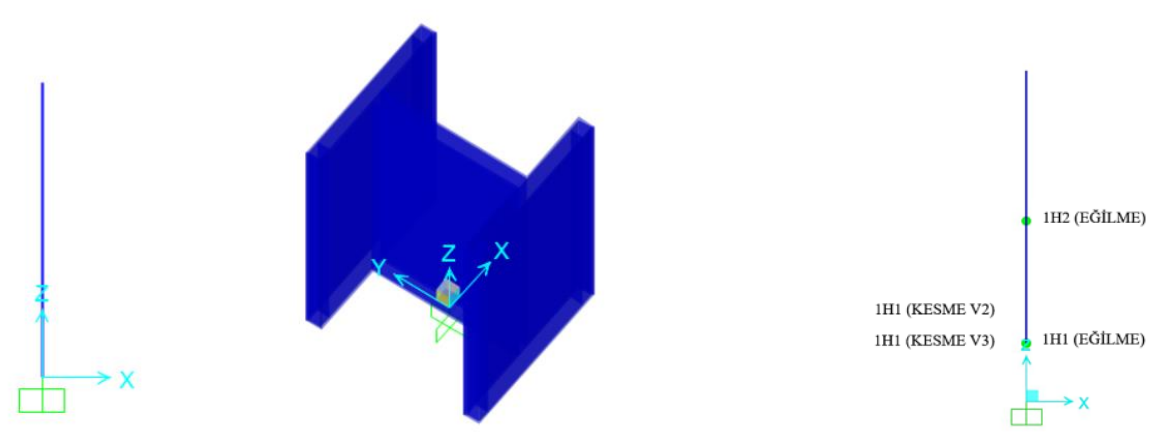

Şekil 9: SAP2000 perde duvar modeli ve plastik mafsal gösterimi

\section{Sonuç}

$>\mathrm{Bu}$ modellerle Maruta [1]'nin test numunelerinin monotonik tepkileri hesaplanmış ve Şekil

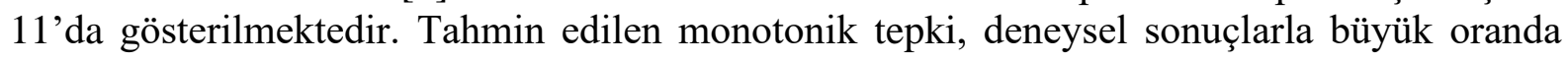
birbirini desteklemektedir.

Kategori seçimi için yapılan hesaplamalarda bu kolonda Kategori 5 uygunluğu sağlanmıştır.

> Çolakoğlu [2] yaptığ çalışmada makalesinin doğruluğunu kontrol etmek için Maruta [1] tarafından yapılan deneysel çalışmayı kendisi öncelikle sonlu elemanlar modeli ile modellemiş ve deneye yakın sonuçlar elde etmiştir. Bu çalışmada Maruta [1] deneysel sonucu, Çolakoğlu [2] sonlu eleman modeli ve SAP2000 sonuçları karşılaştırılmıştır. Yapılan karşılaştırmalara göre, bu çalışmada kullanılan SAP2000 modelinin daha iyi sonuç verdiği ssöylenebilir. 
Karmaşık ve uzun zaman gerektiren analiz ile çözümlenebilen eğilme, ve kesme modeli SAP2000 programı aracılığıyla daha basit halde çözümlenmiştir.

TBDY 2018'de perde duvarların çubuk eleman olarak modellenebilmesi için getirilen perdenin en uzun kol uzunluğunun, toplam perde yüksekliğine oranının 0.5 'ten küçük olma şartının, kesme deformasyonlarının toplam deformasyona dahil edilmesi durumunda geçerli olmadığ bu çalışmada görülmüştür.

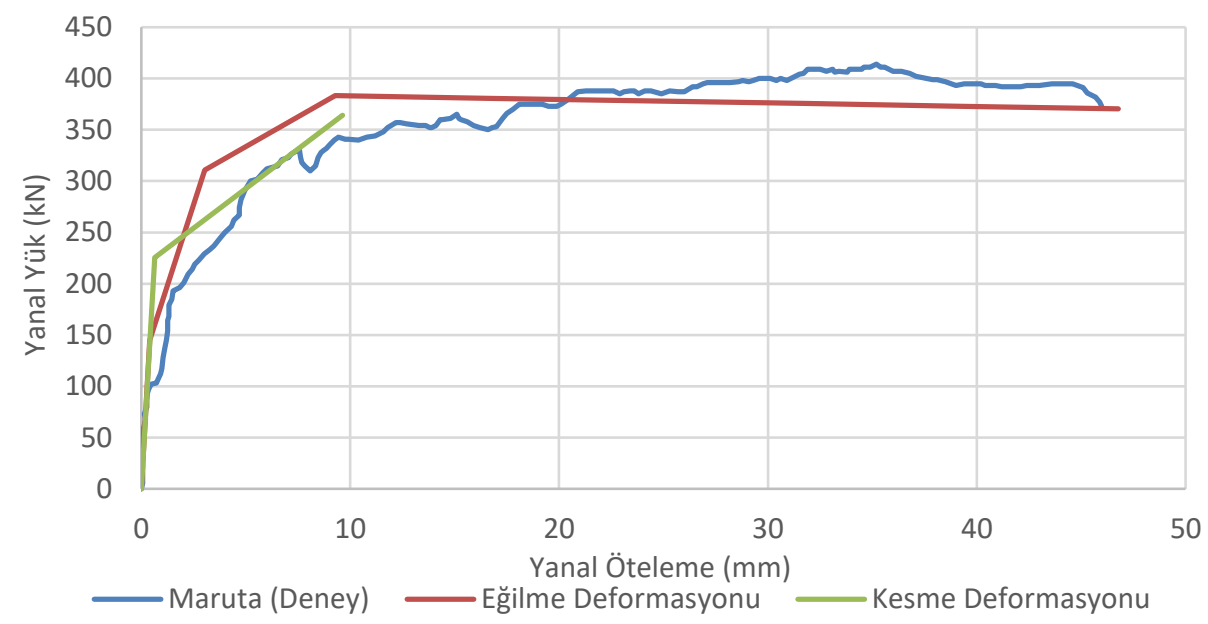

Şekil 10: Kesme kuvveti- yanal öteleme ilişkisi

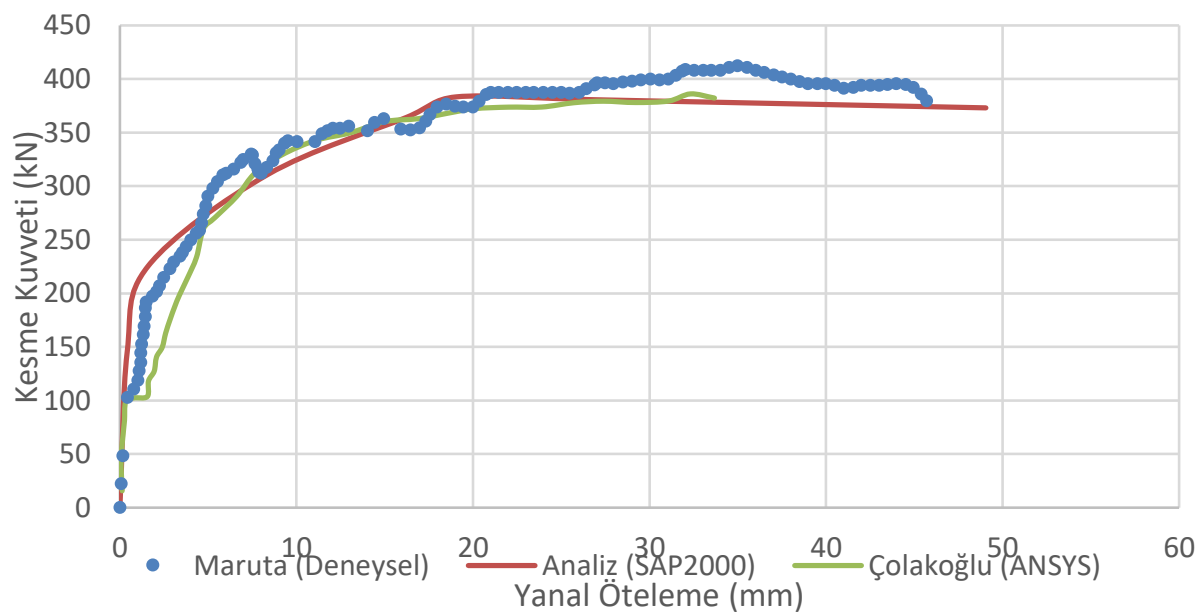

Şekil 11: Kesme kuvveti- yanal öteleme ilişkisi

\section{Referanslar}

[1] Maruta M., Suzuki N., Miyashita T., Nishioka T., Structural capacities of H-shaped RC core wall subjected to lateral load and torsion, 12WCEE2000, 2000.

[2] ACI, 1995, Effect of restraint, volume change and reinforcement on cracking of mass 
concrete, ACI207.2R, ACI Manual of concrete practice, Part 1, American concrete institute, USA .

[3] Wallace J.W., Moehle J.P., Ductility and detailing requirements of bearing wall building, ASCE Journal of Structural Engineering, 118(6), 1625-1644, 1992.

[4] Çolakoğlu H.E., U Şekilli Betonarme Perdelerin Farklı Yük Etkileri Altında Doğrusal Olmayan Davranışı, Teknik Dergi, 2019.

[5] Türk Bina Deprem Yönetmeliği, 2018.

[6] Kent, D.C., Park, R., 1969. Flexural members with confined concrete. ASCE Journal of the Structural Division, 97, ST7.

[7] Vecchio, F. J., and Collins, M. P., "Predicting the Response of Reinforced Concrete Beams Subjected to Shear Using Modified Compression Field Theory," ACI Structural Journal, V. 85, No. 3, May-June 1988, pp. 258-268.

[8] Lodhi M.S. 'Response Estimation of Reinforced Concrete Column Subjected to Lateral Load," Master D. The Ohio State University, 2010.

[9] Sezen H. "Seismic Behavior And Modeling Of Reinforced Concrete Building Columns" Ph.D. Engineering - Civil And Environmental Engineering, University Of California, Berkeley 2002.

[10] Sezen H. "Shear Deformation for Reinforced Concrete Columns", Structural Engineering and Mechanics, 2008.

[11] Gerin, M. and Adebar, P., 2004. "Accounting for Shear in Seismic Analysis of Concrete Structures," Proceedings of the 13th World Conference on Earthquake Engineering. Vancouver, B.C., Canada, Aug. 2004. Paper No. 1747.

[12] Lodhi M.S. 'Response Estimation of Reinforced Concrete Column Subjected to Lateral Load," Master D. The Ohio State University, 2010. 